\title{
Comparative Expression of Key Genes Involved in Steroidal Glycoalkaloid Biosynthesis in Tubers of Two Potato Cultivars, Atlantic and Haryoung
}

\author{
Mekapogu Manjulatha', Hwang-Bae Sohn ${ }^{1}$, Yul-Ho Kim', Su-Jeong Kim', Kwang-Soo Cho', Oh-Keun Kwon ${ }^{1}$, \\ Yong-Ik Jin', Su-Young Hong ${ }^{1}$, Jeong-Hwan Nam', Jong-Taek Suh', Ji-Kyoung Choi ${ }^{1}$, Jin-Cheol Jeong ${ }^{1}$ \\ ${ }^{1}$ Highland Agriculture Research Center, National Institute of Crop Science, RDA, Pyeongchang, 232-955, Korea \\ ${ }^{2}$ Department of Horticultural Crop Research, National Institute of Horticultural \& Herbal Science, RDA, Suwon, 441-440, Korea
}

\begin{abstract}
Quantification of potato glycoalkaloids (PGA) exerting toxicity to humans has some limits if applied to potato breeding populations on a large scale due to its high cost and time consumption. The aim of this study was to investigate key genes involved in PGA biosynthesis and their tuber expression patterns in two potato cultivars, Atlantic with low PGA content (18.6 mg/100g FW) and Haryoung with high PGA content $(40.1 \mathrm{mg} / 100 \mathrm{~g} \mathrm{FW})$, and to test the utility of these PGA gene transcript levels as selectable markers in potato breeding program. Pot grown potato plants of both 'Atlantic' and 'Haryoung' were exposed to drought stress where the transcript accumulation of 3-hydroxy-3-methylglutaryl coenzyme A reductase 1 (Hmgl) and squalene synthase 1 (Pss l) gene was doubled in the tubers of 'Haryoung' at 5days after stress (DAS). The abundance of Hmgl, Pss 1, solanidine galactosyl transferase, solanidine glucosyl transferase and rhamnosyl transferase gene transcripts increased at 10 DAS. Especially, the ratio of Hmgl and PsS 1 transcripts in tubers of 'Haryoung' to those in tubers of 'Atlantic' was higher at 5 DAS compared to that at 10 DAS. The results suggest that drought treatment for 5 days can make a distinct difference in the transcript levels of Hmgl and Pss 1 correlated to PGA levels in tubers of 'Atlantic' and 'Haryoung', and the mRNA level of Hmgl and Pssl can be used as selection markers for breeding potato cultivars with low PGA levels.
\end{abstract}

Keywords 3-Hydroxy-3-methylglutaryl coenzyme A reductase 1, Gene expression marker, Potato glycoalkaloids, Squalene synthase 1

\section{INTRODUCTION}

Steroidal glycoalkaloids are the secondary metabolites present in Solanaceae to serve defense response in plants (Fewell and Roddick 1997; Percival et al. 1994). In potato, $95 \%$ of the total glycoalkaloids are a-solanine and a-chaconine which are triglycosylated products of the same aglycone, solanidine, but differ in their sugar moieties (Friedman and McDonald 1997). Potato glycoalkaloid (PGA) majorly functions to serve for plant defense against bacterial, fungal diseases and against pests (Lachman et al. 2001; Didier et al. 2003; Miller et al. 2003). Also, PGA is toxic to human when it exceeds a safer limit of $20 \mathrm{mg} / 100 \mathrm{~g}$ FW in tuber and PGA poisoning includes severe gastrointestinal disorders, hallucination, partial paralysis to convulsions, coma and even death (Smith et al. 1996). This is caused by inhibiting acetyl choline esterase and impairing membrane integrity (Roddick 1989; Bouarab et al. 2002). PGA is not destroyed during cooking and frying (Smith et al. 1996; Valkonen et al. 1996; Peksa et al. 2006). This needs to be taken as an important consideration as the alteration in the glycoalkaloid level is of major concern for food safety.

Various factors affect PGA accumulation which exerts toxicity to humans. Recently, wild species have been used extensively in potato breeding programs, particularly as a genetic resource of disease and pest resistance due to a narrow genetic diversity of the cultivated potato. The wild species tend to show high level of PGA, which means that potato cultivars derived from crosses with wild germplasm

Received August 30, 2014; Revised September 22, 2014; Accepted September 25, 2014; Published September 30, 2014

*Corresponding author Hwang-Bae Sohn, misson7@korea.kr, Tel: +82-33-330-1870, Fax: +82-33-330-1529 
are at increased risk of exceeding acceptable limit of PGA contents. Sinden et al. (1984) reported that the cultivar Lenape, developed through introgression of the wild species $S$. chacoense Bitter, had to be withdrawn from the market due to high average content of $29 \mathrm{mg} / 100 \mathrm{~g} \mathrm{FW}$ over 10 locations in the United States. In addition, PGA accumulation is caused by development and environmental conditions. The effect of environmental factor on PGA accumulation is supported by the result of Hellenäs et al. (1995) that 'Magnum Bonum' initially having low content of PGA accumulated hazardous level in the variety grown in Sweden. PGA accumulation in major potato cultivars is due to external factors. Such factors including high temperature (Lafta and Lorenzen 2000), light exposure (Dale et al. 1995), light quality (Lin et al. 2010; Tian et al. 2010) and wounding (Bergenstrahle et al. 1992; Choi et al. 1994) increase tuber glycoalkaloid content. In Republic of Korea, potato cultivated in spring is sensitive to drought stress (Bejarano et al. 2000) which alters PGA accumulation. Considering these factors involved in PGA accumulation, the risk of exceeding acceptable limit of PGA contents could increase more highly than usual.

Thus, it is essential to screen commercial cultivars which contain low PGA content in tubers. Usually, PGA content has been analyzed in tubers of breeding clones through PGA assays using high performance liquid chromatography (HPLC) and gas chromatographic/mass spectrometry (Hellenäs et al. 1995; Laurila et al. 1999), which is timeconsuming, expensive and laborious. Potato cultivars with low PGA content can be efficiently selected by using makerassisted selection (MAS) approaches. Until recently, such markers have been identified in potato and high resolution mapping has been made by using genome-wide association study (GWAS) (Sorensen et al. 2008; Stich et al. 2013). The problem of such approaches is that the cultivated potato, Solanum tuberosum L., is an autotetraploid species that displays tetrasomic inheritance (Bradshaw and Mackay 1994; Sleper and Poehlman 2006). To use marker-assisted selection (MAS) in potato breeding program, we need more studies related to quantitative trait loci (QTLs) for

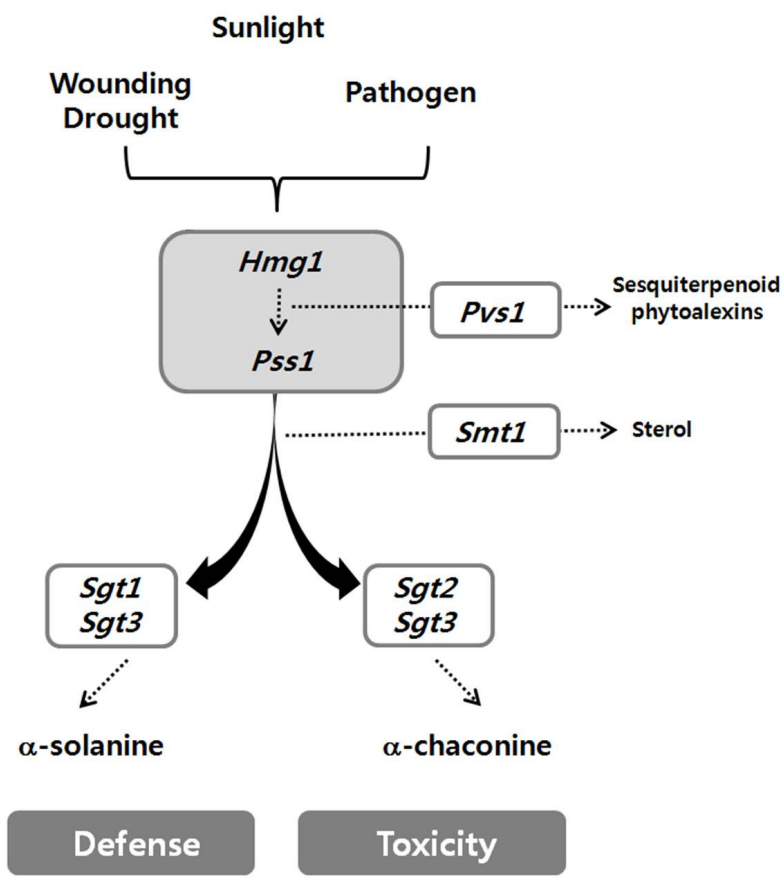

Fig. 1. Steroidal glycoalkaloid biosynthetic pathway in potato plants. Dashed arrows indicate multiple enzymatic steps. 3-hydroxy-3-methylglutaryl coenzyme A reductase 1 ( $H m g l)$, squalene synthase 1 ( $P s s 1)$, vetispiradiene/sesquiterpene synthase $1(P v s l)$, sterol C24-methyltransferase 1 (Smt l) solanidine galactosyl transferase (Sgtl), solanidine glucosyl transferase (Sgt2) and rhamnosyl transferase (Sgt3). Five enzymes that are used in this study are Hmgl, Pssl, Sgt1, Sgt2 and Sgt3. 
PGA content and markers involved in this trait. For this reason it would be relatively easy to apply PGA-biosynthetic gene expression to potato breeding program compared to PGA assay and MAS.

For effective breeding of potato cultivars with low PGA content, there is a need to understand the expression pattern of PGA-biosynthetic genes in the cultivated potato. PGA is bio-synthesized by the sterol branch of mevalonic acid/ isoprenoid pathway (Fig. 1). Many of the enzymes involved in the PGA pathway have been identified, including 3-hydroxy-3-methylglutaryl coenzyme A reductase 1 (Hmgl) and squalene synthase 1 (Pss1) of the mevalonic acid/isoprenoid pathway and solanidine galactosyl transferase (Sgt1), solanidine glucosyl transferase (Sgt2) and rhamnosyl transferase (Sgt3) for PGA glycosylation (Clouse and Sasse 1998; Moehs et al. 1997; Benveniste 2004; McCue et al. 2005; Krits et al. 2007; McCue et al. 2007). PGA accumulation appears to be regulated at different steps in the bio-synthetic pathway in response to environmental conditions. Krits et al. (2007) reported that increased transcript levels of two PGA-biosynthetic genes, Hmgl and Pss 1, were correlated to PGA content.

The aim of this study was to use transcript levels of PGA-biosynthetic genes as selection markers which could be applied to breeding potato cultivars with low PGA content. We investigated expression pattern of PGA-biosynthetic genes in the edible tuber of two commercial cultivars, 'Atlantic' and 'Haryoung', which showed low and high level of PGA, respectively. Our results suggested that Hmgl and Pss 1 involved in PGA biosynthetic pathway can be selected to use the transcript levels of these genes for selection of potato cultivars with low PGA content. This research article gives an efficient selection method of potato cultivars with low PGA content for conventional breeding program.

\section{MATERIALS AND METHODS}

\section{Plant material}

The experiments were carried out with Solanum tuberosum L. cultivar Atlantic and Haryoung. 'Atlantic' was the introduced cultivar with low PGA level, whereas 'Haryoung' was the indigenous cultivar with high PGA level bred at Highland Agriculture Research Center, Rural Development Administration (RDA) in Pyeongchang, Korea. Certified seed-grade potatoes were planted on April 15 and harvested oAugust 5 in 2013 in the area of Jinbu-myeon (altitude $576 \mathrm{~m}$ ) in Pyeongchang-gun of Republic of Korea. To quantify PGA, the skin was peeled by hand from the tuber flesh. For each sample, three biological replicates were prepared, each with the skin and the tuber flesh pooled from five plants. The samples were stored in $-70^{\circ} \mathrm{C}$ deep freezer and freeze-dried.

\section{Extraction and determination of PGA in tubers of 'Atlantic' and 'Haryoung' by HPLC}

PGA content in potato tubers was analyzed by HPLC according to the method described in Friedman et al. (2003). One gram of freeze-dried potato tuber powder was taken in $50 \mathrm{~mL}$ Falcon tube and shaken with $20 \mathrm{ml}$ acetic acid (5\%) for $2 \mathrm{hrs}$. The sample was filtered using filter paper (No. 42, Whatman International, Maidstone, UK) and then extracted with ammonium hydroxide $\left(\mathrm{NH}_{4} \mathrm{OH}\right)$ at $70^{\circ} \mathrm{C}$ for $50 \mathrm{~min}$. The extract was placed at $4^{\circ} \mathrm{C}$ refrigerator for $24 \mathrm{hrs}$, and then centrifuged at $13,000 \mathrm{rpm}$ at $4{ }^{\circ} \mathrm{C}$ for 10 $\mathrm{min}$. The precipitate was dissolved in methanol, and then extracted with the same method. The supernatants were filtered using $0.45 \mu \mathrm{m}$ PVDF syringe filter (PALL, USA), and then subjected to HPLC analysis (2695 Alliance HPLC, Waters Co., MA, USA).

The samples were injected onto Inertsil $\mathrm{NH}_{2}$ column ( $5 \mu \mathrm{m}, 4.0 \times 250 \mathrm{~mm}$, GL Science, Tokyo, Japan) using actonitrile $/ 20 \mathrm{mM} \mathrm{KH}_{2} \mathrm{PO}_{4}(80: 20, \mathrm{v} / \mathrm{v})$ at a flow rate of 0.7 $\mathrm{mL} / \mathrm{min}$. PGA were identified by their retention time and by absorption spectra at $208 \mathrm{~nm}$ using a photodiode array detector (2996 PDA detector, Waters Co., MA, USA). For quantification of PGA, a-chaconine (Extrasynthase Co., Genay cedex, France) and a-solanine (Sigma-Aldrich Co., Mo, USA) were dissolved in methanol. Four working calibration solutions ranging from 3.1 to $25.0 \mathrm{mg} / \mathrm{L}$ were prepared by diluting stock solutions of the external standards.

\section{Drought treatment}

Two sets of plants from 'Atlantic' and 'Haryoung' were grown in pots filled with perlite soil-less medium in 
containment conditions. Plants were well watered until 70 days after planting. Drought stress was imposed by withholding water to one set of plants from 70 days after planting which is the tuber initiation stage. The other set of plants were irrigated and maintained as unstressed control plants. Leaf and tuber sample was collected from both control and stress plants at 5, 10 and 20 days after imposing drought stress (DAS). Tuber samples were washed, cut into pieces of $3 \mathrm{~cm}$ diameter and frozen in liquid nitrogen.

\section{Quantitative Real Time PCR}

Total RNA was isolated from the tuber sample of both control and drought stress imposed plants of 'Atlantic' and 'Haryoung'. RNA from leaves was isolated using RNeasy Plant Mini kit (Qiagen Sciences, Germantown, MD, USA) and from tuber using PureLink ${ }^{\circledR}$ Plant RNA Reagent (Life technologies Korea LLC, Seoul, Korea). Two micrograms of total RNA was reverse-transcribed into cDNA using Superscript reverse transcriptase enzyme (Invitrogen, Life technologies Korea LLC, Seoul, Korea). Five key genes were selected in PGA pathway and their expression pattern was studied after treating both 'Atlantic' and 'Haryoung' with drought stress. The expression pattern of these genes was analyzed by Quantitative Real-Time PCR using gene specific primers (Table 1) and Thunderbird ${ }^{\mathrm{TM}}$ SYBR $\mathbb{}$ qPCR Mix (Toyobo Biotechnologies Co., Osaka, Japan) according to manufacturer's protocols. Each PCR was performed with three technical replicates and three sample replicates. Relative abundance was calculated with the $\triangle$
$\mathrm{C}_{\mathrm{T}}$ method (Livak and Schmittegen 2001) using 18s rRNA for template normalization. The average $\mathrm{C}_{\mathrm{t}}$ standard was set around 0.4. The graphs were represented as fold increase in the level of expression over the respective control sample.

\section{Isolation of Sgt1, Sgt2 and Sgt3}

Total RNA was extracted from the leaves of 'Atlantic' and 'Haryoung' plants using RNeasy plant mini kit (Qiagen). cDNA was synthesized using Superscript ${ }^{\mathrm{TM}}$ Reverse Transcriptase enzyme (Invitrogen) and OligodT primer (Enzynomics co Ltd, Daejeon, Korea). Specific primers were designed for Sgt1 (U82367), Sgt2 (DQ218276) and Sgt3 (DQ266437) resulting to respective fragments of about $1,441 \mathrm{bp}, 1,434 \mathrm{bp}$ and 1,467 bp. Primers were designed for the complete coding sequence of Sgt1, whereas two halves with fragment sizes of $753 \mathrm{bp}$ and $804 \mathrm{bp}$ were designed in the case of Sgt 2 and 749 bp and 750 bp for Sgt3.

The gene of interest was amplified using the cDNA template from 'Atlantic' and 'Haryoung' with the genespecific primers. The amplified products were column purified using gel elution kit (Qiagen) and cloned into pTOP vector using TOPcloner TA/Blunt kit for PCR cloning (Enzynomics co Ltd., Daejeon, Korea) and sequenced. Homology search was done for deduced amino acid sequence similarity / identity (www.ncbi.nlm.nih.gou/blastp). Sequences were aligned with the existing gene in the database for the gene identity and analyzed for any substitutions using CLC Main Workbench 5.7.1 software.

Table 1. Primer sequence of one housekeeping gene and PGA-biosynthetic genes used for qRT-PCR analysis.

\begin{tabular}{ccc}
\hline \hline Gene $^{\mathrm{z})}$ & Primer forward $\left(5^{\prime} \rightarrow 3^{\prime}\right)$ & Primer reverse $\left(5^{\prime} \rightarrow 3^{\prime}\right)$ \\
\hline$H m g 1$ & GGGTACAGTGGGTGGTGGAAC & CACCAGCAAGAACAGAACC \\
Pss 1 & CTTGCAGAGACTCGGGAACCTTG & CGGTTGCCAGAAAGTTGTGC \\
$S g t 1$ & GGTTTACAGACCTCACAAGCAGCC & CAATGCCATAGCTTCGTTCCTCCG \\
$S g t 2$ & GCAGTCGGAGGATTCATGACACAC & TCGATATCTCAGCACCTCCGTTGG \\
Sgt3 & GTTTATCATCCAAGGCTGGGCACC & CCAATAGCAAGGCCAAGTGTCTCC \\
$18 \mathrm{~s}$ rRNA & ATCCTGCCAGTAGTCATATGC & CTACGGTTATTCGAGTAGTAG \\
\hline
\end{tabular}

z) 3-hydroxy-3-methylglutaryl coenzyme A reductase 1 (Hmgl), squalene synthase 1 (Pss1), vetispiradiene/sesquiterpene synthase $1(P v s 1)$, sterol C24-methyltransferase 1 (Smt1) solanidine galactosyl transferase (Sgt1), solanidine glucosyl transferase $(S g t 2)$ and rhamnosyl transferase $(S g t 3)$. 


\section{RESULTS}

\section{Characteristics and PGA contents of two potato cultivars,} Atlantic and Haryoung

In a previous study (Kim et al. 2014), we showed the total PGA contents of the potato tubers were 16.5 in Goun, 19.7 in Atlantic, 21.2 in Hongyoung, 45.7 in Jayoung, 46.2 in Haryoung and $47.7 \mathrm{mg} / 100 \mathrm{~g} \mathrm{FW}$ in Superior. As expected, contents of a-solanine, a-chaconine and total PGA which were determined in field-grown tubers by HPLC were higher in tuber peel and flesh of 'Haryoung' compared with those of 'Atlantic' (Fig. 2). In addition, 'Haryoung' showed similar maturity with 'Atlantic' (Table 1) which exhibited low PGA level. Considering PGA contents and maturity of two potato cultivars, we investigated expression pattern of PGA-biosynthetic genes in the edible tuber of the above mentioned cultivars.

\section{Expression pattem of PGA-biosynthetic genes in tubers of 'Atlantic' and 'Haryoung' under water-deficit compared with well-watered condition}

Bejarano et al. (2000) reported that PGA accumulation was induced under drought conditions. Thus, we used drought treatment in 'Atlantic' and 'Haryoung', for the selection of genes which could be applied for screening potato cultivars with high PGA content. In the present study, the expression pattern of PGA-biosynthetic genes was determined in the tuber of Atlantic' and 'Haryoung' plants exposed to drought stress for various time intervals 5, 10 and 20 days after drought stress (DAS). Gene expression analysis of PGA-biosynthetic genes in tubers of 'Atlantic' and 'Haryoung' exposed for 5 DAS revealed similar transcript levels in tubers of 'Atlantic' with well-watered condition whereas tubers of 'Haryoung' exhibited increased transcript levels of two genes. The genes, Hmgl and Pss 1 ,
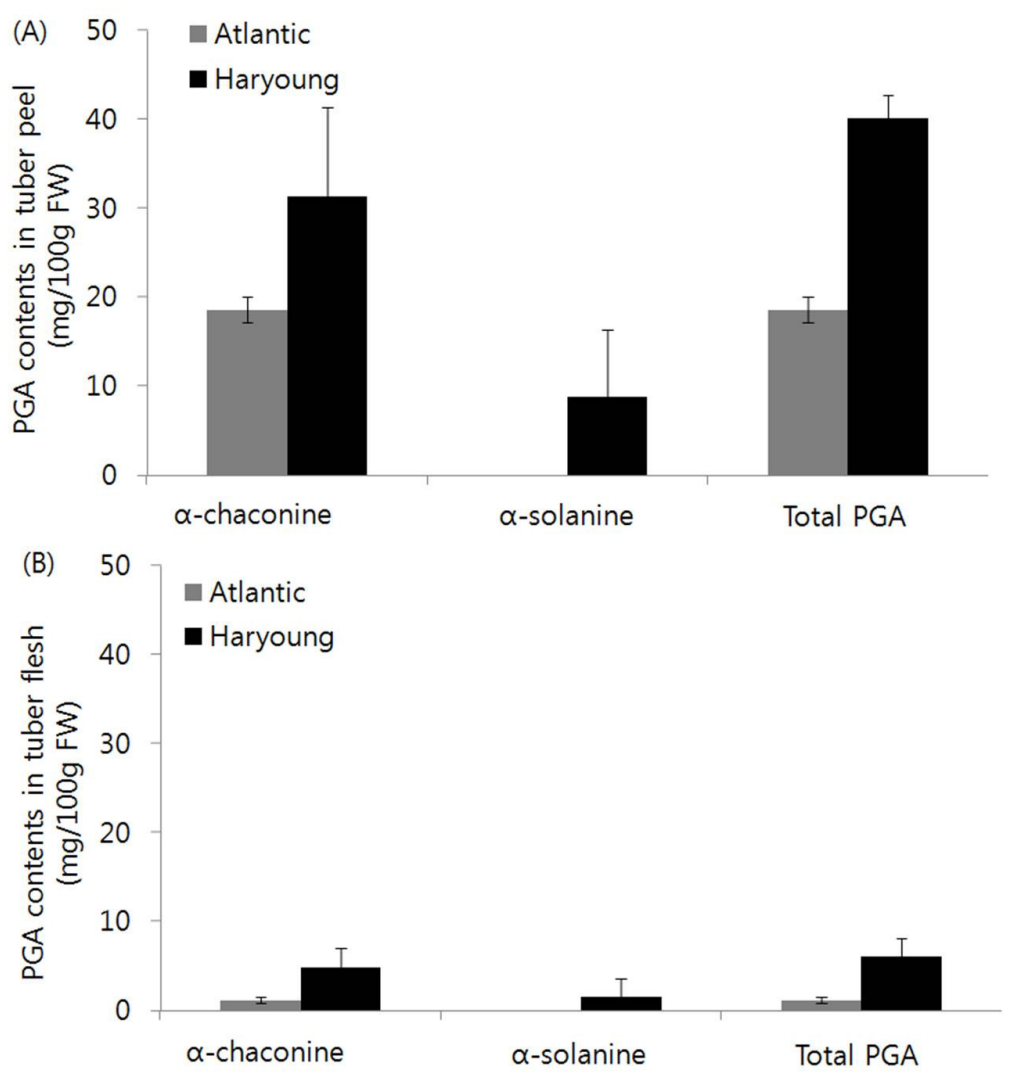

Fig. 2. Comparison of potato glycoalkaloid (PGA) contents in tuber peel (A) and flesh (B) of two potato cultivars, Atlantic and Haryoung. For each sample, three biological replicates were prepared, each with the skin and the tuber flesh pooled from five plants. The PGA content was quantified by HPLC. PGA values are the means \pm SD from three replications. 
in tubers of 'Haryoung' increased 2.4- and 2.6-fold, respectively. A significant difference was observed in the transcript levels of five key genes in tubers of 'Atlantic' and 'Haryoung' exposed to drought stress for 10 days compared to well-watered condition. The transcript levels of $\mathrm{Hmgl}$, Pss1, Sgt1, Sgt2 and Sgt3 increased to 2.3-, 2.5-, 5.1-, 3.7and 4.4-fold in tubers of 'Atlantic' and 1.7-, 8.6-, 2.8-, 5.8and 10.7-fold in tubers of 'Haryoung', respectively. At 20 DAS, expressions of the genes in two cultivars were repressed (Table 3). However, the drought treatment did not alter the transcript levels of PGA biosynthetic genes in potato leaves of 'Haryoung' and 'Atlantic' (data not shown).

\section{Expression ratio of key genes involved in steroidal glycoalkaloid biosynthesis in tuber}

A difference in the ratio of five key genes expression between the tubers of 'Haryoung' and that of 'Atlantic' exposed to drought stress for 5 and 10 days was noted. Higher expression of Hmg1, Pss 1, Sgt1, Sgt2 and Sgt 3 were indicated by the respective higher values, 12-, 3.7-, 1.7-, 3.2- and 2.2-fold compared withthose in the tubers of 'Atlantic' exposed for 5 DAS. At 10 DAS, Pss 1, Sgt2 and
Sgt3 in tubers of 'Haryoung' were expressed higher than in the tubers of 'Atlantic'. Among the genes with increased transcripts, the transcript level of Pss 1 increased by 3.4-fold, which suggests that the expression level of Pss 1 could be used for selecting potato cultivars with low PGA content. In addition, the increase in the transcript abundance of $S g t 1, S g t 2$ and $S g t 3$ at 10 DAS indicated their direct involvement in PGA accumulation (Fig. 3). These results showed that drought treatment made a significant difference in PGA-biosynthetic gene expression in tubers of 'Atlantic' and 'Haryoung'. The PGA-biosynthetic genes, Hmgl and Pss, involved in PGA accumulation could be used for the selection of potato cultivars with low PGA content easier than PGA assays by analytical instruments.

\section{Comparison of SGT1, SGT2 and SGT3 sequences from 'Atlantic' and 'Haryoung'}

Initially, cDNA of the selected key genes in PGAbiosynthetic pathway $S g t 1, S g t 2$ and $S g t 3$ was prepared from the RNA isolated from the leaves of 'Atlantic' and 'Haryoung'. Isolation of $S g t l$ was done by the amplification of cDNA with $S g t 1$ specific primers, producing a $1.44 \mathrm{~kb}$

Table 2. Characteristics of Haryoung and Atlantic potato cultivars.

\begin{tabular}{cccccc}
\hline \hline Cultivar & $\begin{array}{c}\text { Registration } \\
\text { year }\end{array}$ & Maturity & $\begin{array}{c}\text { Total PGA in } \\
\text { tubers }(\mathrm{mg} / 100 \mathrm{~g} \mathrm{FW})\end{array}$ & Cross combination & Utilization type \\
\hline Haryoung & 2005 & Medium & 46.2 & Atlantic $\times$ Superior & Table potato \\
Atlantic & 1995 & Medium & 19.7 & B5141-6 $\times$ Wauseon & Potato chip \\
\hline
\end{tabular}

Table 3. The relative transcript levels of PGA biosynthetic genes in potato tubers of 'Atlantic' and 'Haryoung' under drought stress compared to well-watered condition.

\begin{tabular}{ccccccc}
\hline \hline \multirow{2}{*}{$\begin{array}{c}\text { Potato } \\
\text { Cultivar }\end{array}$} & $\begin{array}{c}\text { Days After } \\
\text { Stress }\end{array}$ & Hmgl & Pss 1 & Sgt1 & Sgt2 & Sgt3 \\
\hline Atlantic & 5 & $0.2 \pm 0.1$ & $0.7 \pm 0.2$ & $0.4 \pm 0.1$ & $0.4 \pm 0.1$ & $0.4 \pm 0.2$ \\
& 10 & $2.3 \pm 0.3$ & $2.5 \pm 0.2$ & $5.1 \pm 1.2$ & $3.7 \pm 0.2$ & $4.4 \pm 0.3$ \\
& 20 & $0.7 \pm 0.2$ & $0.3 \pm 0.1$ & $0.8 \pm 0.3$ & $0.8 \pm 0.3$ & $0.8 \pm 0.2$ \\
Haryoung & 5 & $2.4 \pm 0.3$ & $2.6 \pm 0.2$ & $0.6 \pm 0.1$ & $1.1 \pm 0.3$ & $0.9 \pm 0.2$ \\
& 10 & $1.7 \pm 0.4$ & $8.6 \pm 1.2$ & $2.8 \pm 0.7$ & $5.8 \pm 0.4$ & $10.7 \pm 1.2$ \\
& 20 & $0.2 \pm 0.1$ & $0.3 \pm 0.1$ & $0.2 \pm 0.1$ & $0.5 \pm 0.1$ & $0.1 \pm 0.1$ \\
\hline
\end{tabular}

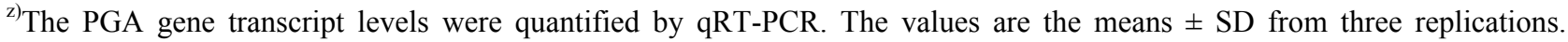
3-hydroxy-3-methylglutaryl coenzyme A reductase 1 (Hmgl), squalene synthase 1 (Pss1), vetispiradiene/sesquiterpene synthase $1(P v s 1)$, sterol C24-methyltransferase $1(\operatorname{Smtl})$ solanidine galactosyl transferase (Sgt1), solanidine glucosyl transferase $(S g t 2)$ and rhamnosyl transferase $(S g t 3)$. 
fragment which was then sequenced. Alignment comparison of the amino acid SGT1 sequence of 'Atlantic' and 'Haryoung' with reference gene, showed a highly similar sequence in 'Haryoung' with reference gene whereas 'Atlantic' revealed three substitutions. These sequence variations in 'Atlantic' were observed at amino acid position 54 (arginine is substituted with lysine), 213 (glutamic acid with leucine) and 309 (alanine with serine) (Fig. 4). There was no difference observed in predicted phosphorylation or glycosylation sites in SGT1 protein from 'Atlantic'. Isolation of Sgt2 and Sgt3 was done by amplifying the coding sequence in two halves which produced the amplicons of $753 \mathrm{bp}$ and $804 \mathrm{bp}$ in $\mathrm{Sgt} 2$ and $749 \mathrm{bp}$ and 750 bp for Sgt3 which were then sequenced. Amino acid sequence alignment of $S g t 2$ and $S g t 3$ from 'Atlantic' and 'Haryoung' with reference gene showed a 100\% homology of both genes in 'Atlantic' and 'Haryoung' (data not shown).

\section{DISCUSSION}

The PGA contents in tubers of 'Haryoung' were higher than those of 'Atlantic' which were grown in the field located in Jinbu-myeon (Fig. 2). These results are supported by the results of Kim et al. (2014) that total PGA contents in tubers of 'Atlantic' and 'Haryoung' among major potato cultivars in Republic of Korea were 19.7 and $46.2 \mathrm{mg} / 100 \mathrm{~g} \mathrm{FW}$, respectively. Also, PGA contents in tubers of 'Haryoung' were higher compared with those in tubers of 'Atlantic' which were grown in Gangneung and Daegwallyeong (data not shown). These results suggested that 'Atlantic' could be cultivated safely, whereas special care is needed in cultivation of 'Haryoung' with higher PGA content in various cultivation environments. Thus, we selected 'Atlantic' and 'Haryoung', for investigating the expression pattern of PGA-biosynthetic genes.

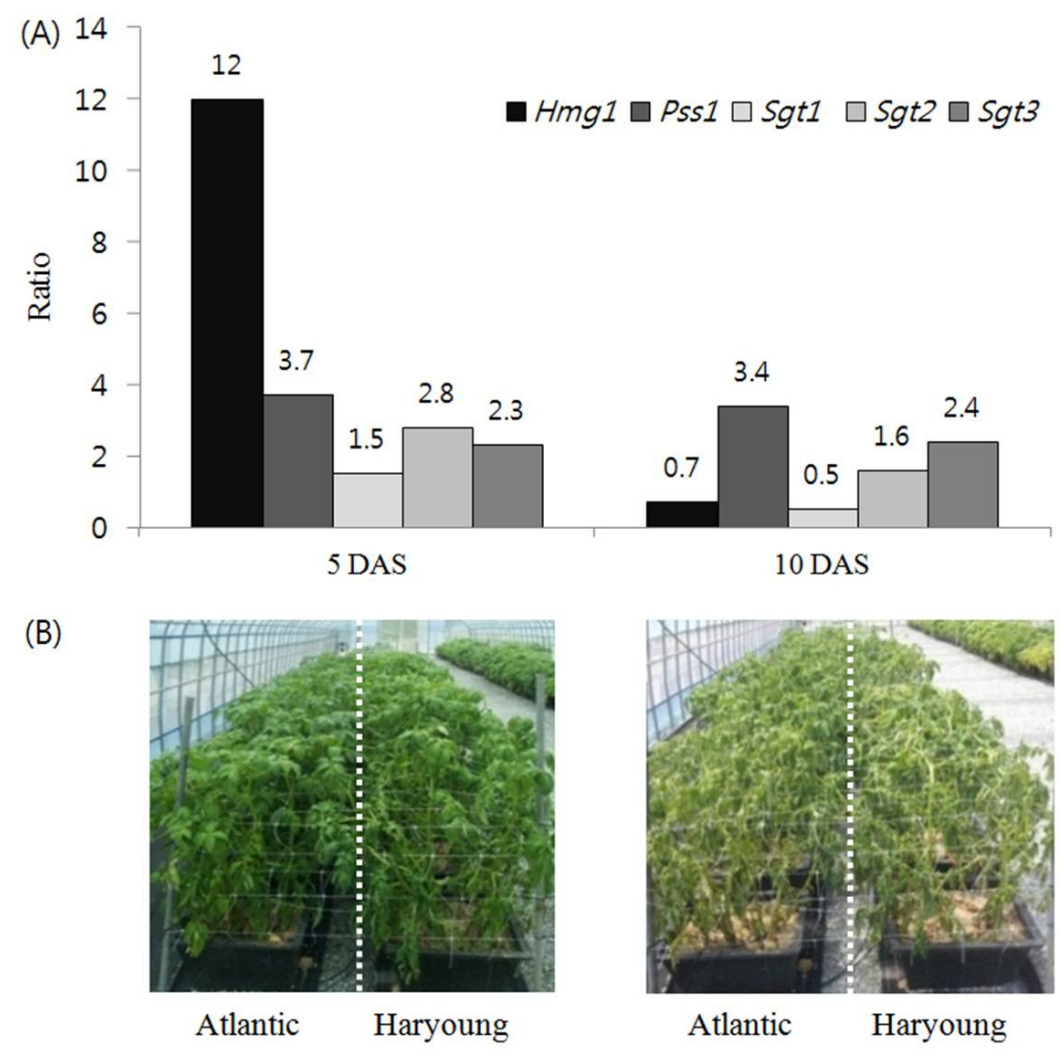

Fig. 3. Effect of drought stress and treatment time on the expression of PGA genes in tubers of potato cultivars, Atlantic and Haryoung. (A) The ratio of average transcript level in 'Haryoung' to that in 'Atlantic' under drought stress for five and ten days. 3-hydroxy-3-methylglutaryl coenzyme A reductase 1 ( Hmgl), squalene synthase 1 (Pss I), solanidine galactosyl transferase (Sgt1), solanidine glucosyl transferase (Sgt2) and rhamnosyl transferase (Sgt3). (B) Phenotype of aerial parts in 'Atlantic' and 'Haryoung' under 5 and 10 DAS. DAS = days after drought stress 
Expression analysis of PGA-biosynthetic genes could be applied as a selection tool for potato cultivars with low PGA content, especially in organisms with autotetraploid genomes such as $S$. tuberosum L. Stress treatment has been proven useful in enhancing gene expression involved in specific biological processes, or that are expressed in unique organs and tissue. Combination of these two techniques would accelerate the screening of genes in cultivated potatoes that are amenable to selection of potato cultivars with low PGA content. The advantage of this technique is that it can be easily tested by drought treatment in the pots and qRT-PCR analysis. We note that the use of gene expression analysis is limited to some extent such that it can only identify components of biological processes that are transcriptionally regulated.

qRT-PCR analysis of thedrought-treated potatoes successfully uncovered mRNAs involved in PGA accumulation (Table 3). Two genes, Hmgl and Pss, involved directly in PGA biosynthesis pathway catalyze the first step in PGA biosynthesis that increases in response to external stress including wounding, plant disease, developmental and light stimuli (Yang et al. 1991; Korth et al. 2000). HMGR1 proteins have been shown to be related to PGA content (Choi et al. 1994; Dale et al. 1995; Percival et al. 1994). In addition, Pss 1 is a part of the PGA biosynthetic pathway, and its expression would be expected to be increased in accordance with the changes of PGA. Hence, the use of expression levels of $\mathrm{Hmg} \mathrm{I}$ and Pss 1 under drought stress increases the efficiency of selecting potato clones with low PGA content which can be cultivated in various environmental conditions.

Drought treatment for 5 and 10 days resulted in the higher expression of genes encoding PGA biosynthetic enzymes in tubers of 'Haryoung' compared to those in tubers of 'Atlantic', indicating that drought treatment made a significant difference in the gene expressions between 'Haryoung' and 'Atlantic' (Table 3). One exception to this trend was $\mathrm{Hmgl}$, which increased 2.3-fold in tubers of 'Atlantic' and 1.7-fold in tubers of 'Haryoung'. Drought treatment for 10 days induced 8.6-fold transcripts of Pss 1 in tubers of 'Haryoung', which negatively affected the transcripts of Hmg1. Ginzberg et al. (2012) showed that

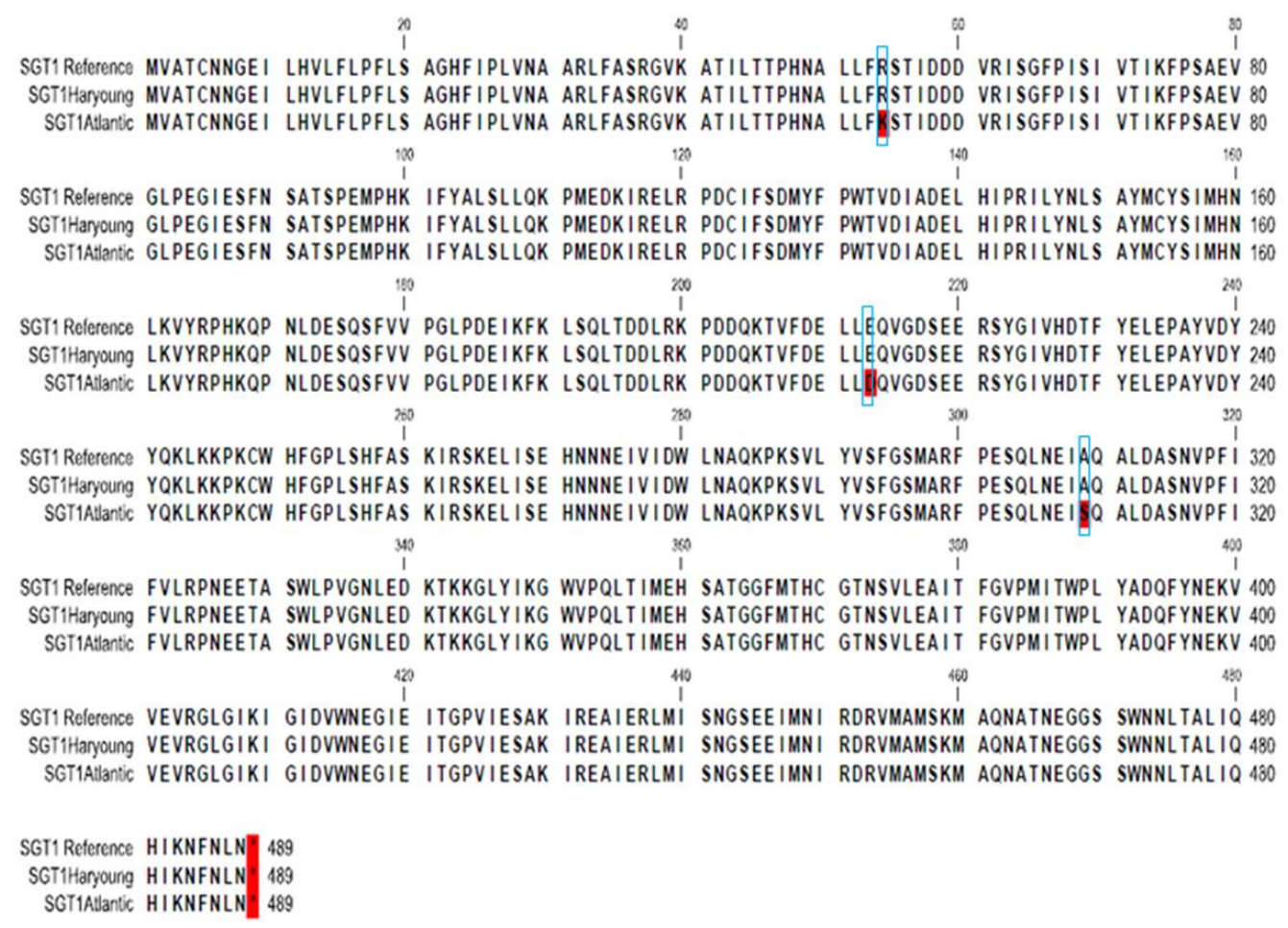

Fig. 4. Comparison of deduced amino acid sequence of SGT1 from potato cultivars, Atlantic and Haryoung with reference sequence. Substitutions in 'Atlantic' are shown in the box. 
over-expression of Pss 1 causes a reduction of the transcript levels of Hmgl, and it seems likely that this gene is regulated by a feedback regulation cycle. Also, posttranscriptional regulation of HMGR activity has been shown through in vitro assay, which showed that this protein was inactivated via phosphorylation at position 590 of potato HMGR1 (Mackintosh et al. 1992; Dale et al. 1995). Although inactivation of HMGR1 protein needs to be considered, our results indicate that the transcript level of Hmgl should contribute to PGA synthesis.

There was a difference observed in ratio of the key gene expression in tubers of 'Haryoung' to those in tubers of 'Atlantic'. At 5 DAS, the relative transcript levels of $\mathrm{Hmg} 1$ and Pss1 showed 12- and 3.7-fold increase in tubers of 'Haryoung', respectively, compared with those in tubers of 'Atlantic'. Drought stress for 10 days increased 3.4-fold in the relative transcript level of $P s s 1$ (Fig. 3). This coordinated expression of the isoprenoid key enzymes, $H m g l$ and Pss 1 facilitates precursor flow to PGA biosynthesis. The activities of Pvs1, Pss 1 and Smt 1 are the committed steps for the various isoprenoid compounds (Fig. 1). The Pss 1 transcript level, which competes with pvs 1 on the same substrate, farensyl-PP, increased with Hmgl transcript levels at 5 DAS (Fig. 3). These results were comparable with those of Krits et al. (2007) where the potato genotypes exhibiting different levels of PGA content showed an association between high PGA levels and high expression of Hmgl and Pssl. The association of the gene expression with PGA contents was supported by the higher PGA contents in the tubers of 'Haryoung' than 'Atlantic' (Fig. 2). These results suggested that the expression pattern of Hmgl and Pss 1 could be used as screening markers to avoid potato cultivars with high PGA content. Especially, the use of Pss 1 as the screening marker is supported by the expression pattern of PGA biosynthetic genes, which showed that the expression level of Pss1 in tubers of 'Haryoung' was higher than that in tubers of 'Atlantic' at 5 and 10 DAS.

The drought treatment did not alter the transcript levels of PGA biosynthetic enzymes in potato leaves of 'Haryoung' and 'Atlantic' (data not shown). PGA is present in all parts of the plant and higher levels are present in the intensive metabolically active tissues like leaves, stems, fruits and flowers but their levels are less in tubers comparatively (Peksa et al., 2002). Interestingly, we failed to find significant increase in the transcript levels of key genes involved in PGA biosynthesis in drought-treated leaves of 'Haryoung' and 'Atlantic'. This may be due to an increase in expression of PGA biosynthetic genes before 5 DAS in leaves of 'Haryoung' and 'Atlantic'.

In addition, increase in the transcript abundance of $S g t 1$, Sgt2 and Sgt 3 at 10 DAS indicated their direct involvement in glycoalkaloid accumulation. Increased transcript levels of Hmgl and Pss 1 in the upstream of the pathway under drought stress showed that they might play a role in the regulation of $S g t 1, S g t 2$ and $S g t 3$ levels in the downstream of the pathway. The expression levels of Sgt1 and Sgt2 were relatively associated with the content of solanine to chaconine ratio respectively in tuber (Fig. 4). Thus, we isolated three key genes that are directly involved in the formation of PGA; Sgt1, Sgt2 and Sgt3 to check for any sequence variations which determine the varied accumulation of PGA in two low and high PGA exhibiting cultivars. The deduced amino acid sequence alignments of $S g t 2$ and $S g t 3$ between 'Atlantic' and 'Haryoung' showed highly homologous sequence with $100 \%$ similarity, whereas amino acid alignment of Sgt1 showed three substitutions in 'Atlantic'. However, there was no variation in the predicted phosphorylation and glycosylation sites in SGT1 protein from 'Atlantic'. Manrique-Carpintero et al. (2013) observed the similar kind of synonymous and non-synonymous substitutions in HMGR1 and PSS1 in various potato cultivars, but it was unclear whether those substitutions attributed for the varied accumulation of PGA. Hence, it shows that the nucleotide sequence of $S g t 2$ and $S g t 3$ and the amino acid substitutions encoded in the cDNA for Sgt1 in 'Atlantic' may not contribute to the difference in the glycoalkaloid biosynthetic efficiencies of two cultivars.

In conclusion, our results suggest that (i) drought treatment for 5 days can make a distinct difference in the Hmgl and Pss 1 transcript levels correlated to PGA levels in tubers of 'Atlantic' and 'Haryoung' and (ii) mRNA level of Hmgl and Pss 1 can be used as selection markers for breeding potato cultivars that have low PGA levels. In future, the expression pattern of the selected genes, Hmgl and Pss 1 will be applied to investigate the association of 
gene expression level with PGA accumulation in 24 potato cultivars bred in RDA, Korea.

\section{ACKNOWLEDGMENTS}

This work was supported by a grant from the Agricultural R\&D Project by Rural Development Administration, Republic of Korea. The ATIS code of detailed project is PJ00876404.

\section{REFERENCES}

Bejarano L, Mignolet E, Devaux A, Espinola N, Carrasco E, Larondelle Y. 2000. Glycoalkaloids and drought stress on the a-solanine and a-chaconine contents of potatoes. J. Sci. Food Agric. 80: 2096-2100.

Benveniste P. 2004. Biosynthesis and accumulation of sterols. Annu. Rev. Plant Biol. 55: 429-457.

Bergenstrahle A, Tillberg E, Jonsson L. 1992. Characterization of UDP-glucose: solanidine glycosyltransferase and UDP-galactose:solanidine galactosyltransferase from potato tuber. Plant Sci. 84: 35-44.

Bouarab K, Melton R, Peart J, Baulcombe D, Osbourn A. 2002. A saponin-detoxifying enzyme mediates suppression of plant defences. Nature 418: 889-892.

Bradshaw JE, Mackay GR. 1994. Breeding strategies for clonally propagated potatoes. P. 467-497. In: J.E. Bradshw and G.R. Mackay (ed.) Potato Genetics. CAB International, Wallingford, UK.

Choi D, Bostock RM, Avdiushko S, Hilderand DF. 1994. Lipid-derived signals that discriminate wound- and pathogen-responsive isoprenoid pathways in plants: Methyl jasmonate and the fungal elicitor arachidonic acid induce different 3-hydroxy-3-methylglutaryl-coenzyme A reductase genes and antimicrobial isoprenoids in Solanum tuberosum L. Proc. Natl. Acad. Sci. USA 91: 2329-2333.

Clouse SD, Sasse JM. 1998. Brassinosteroids: Essential regulators of plant growth and development. Annu. Rev. Plant Physiol. Plant Mol. Biol. 49: 427-451.

Dale S, Arro M, Beccerra B, Morrice NG, Boronat A, Hardie DG, Ferrer A. 1995. Bacterial expression of the catalytic domain of 3-hydroxy-3-methlglutaryl Co-A reductase (isoform HMGR1) from Arabidopsis thaliana, and its inactivation by phosphorylation at Ser577 by Brassica oleracea 3-hydroxy-3methylglytaryl CoA reductase kinase. Eur. J. Biochem. 233: 506-513.

Fewell AM, Roddick JG. 1993. Interative antifungal activity of the glycoalkaloids a-solanine and a-chaconine. Phytochemistry $33:$ 323-328.

Friedman M, Mcdonald GM. 1997. Potato glycoalkaloids: chemistry, analysis, safety and plant physiology. Crit. Rev. Plant Sci. 16: 55-132.

Friedman M, Roitman JN, Kozukue N. 2003. Glycoalkaloid and calystegine contents of eight potato cultivars. J. Agric. Food Chem. 51: 2964-2973.

Ginzberg I, Muddarangappa T, Fogelman E, Damirel U, Mweetwa AM, Tokuhisa J, Veilleux RE. 2012. Induction of potato steroidal glycoalkaloid biosynthetic pathway by overexpression of cDNA encoding primary metabolism HMG-CoA reductase and squalene synthase. Planta 235: 1341-1353.

Hellenäs KE, Branzell C, Johnsson H, Slanina P. 1995. Glycoalkaloid content of early potato varieties. J. Sci. Food Agric. 67: 125-128.

Kim YH, Kim GH, Ji HR, Lee YY, Park HM, Kwon OK, Kim SJ, Sohn HW, Hong SY, Nam JH, Kwon KB, Seo JT, Jeong JC. 2014. Glycoalkaloids content influence by tuber parts and storage period in major potato cultivars of Korea. Korean J. Breed. Sci. In Press.

Korth KL, Jaggard DAW, Dixon RA. 2000. Developmental and light-regulated post-translational control of 3-hydroxy3-methyl-glutaryl-CoA reductase levels in potato. Plant J. 23: 507-516.

Krits P, Fogelman E, Ginzberg I. 2007. Potato steroidal glycoalkaloid levels and the expression of key isoprenoid metabolic genes. Planta 227: 143-150.

Lachman J, Hamouz K, Orsák M, Pivec V. 2001. Potato glycoalkaloids and their significance in plant protection and human nutrition-review. Rostl. Výr. 47: 181-191.

Lafta AM, Lorenzen JH. 2000. Influence of high temperature and reduced irradiance on glycoalkaloid levels in potato leaves. J. Amer. Soc. Hort. Sci. 125:563-566

Laurila J, Laakso I, Väänänen T, Kuronen P, Huopalahti R, Pehu E. 1999. Determination of solanidine- and tomatidinetype glycoalkaloid aglycons by gas Chromatography/ Mass spectrometry. J. Agric. Food Chem. 47: 2738-2342. Livak KJ, Schmittgen TD. 2001. Analysis of relative 
expression data using real-time quantitative PCR and the 2- $\triangle \triangle C^{T}$ method. Methods 25: 402-408.

Mackintosh RW, Davies SP, Clarke PR, Weekes J, Gillespie JG, Gibb BJ, Hardie DG. 1992. Evidence for a protein kinase cascade in higher plants. 3-Hydroxy-3-methlglutaryl Co-A reductase. Eur. J. Biochem. 209: 923-931.

Manrique-Carpintero NC, Tokuhisa JG, Ginzberg I, Hoolidat JA, Veilleux RE. 2013. Sequence diversity in coding regions of candidate genes in the glycoalkaloid biosynthetic pathway of wild potato species. Genetics 3: 1467-1479.

McCue KF, Shepherd LVT, Allen PV, Maccree MM, Rockhold DR, Corshini DL, Davies HV, Belknap WR. 2005. Metabolic compensation of steroidal glycoalkaloid biosynthesis in transgenic potato tubers: using reverse genetics to confirm the in vivo enzyme function of a steroidal alkaloid galactosyltransferase. Plant Sci. 168: 267-273.

McCue KF, Allen PV, Shepherd LVT, Blake A, Maccree MM, Rockhold DR, Novy RG, Stewart D, Davies HV, Belknap WR. 2007. Potato glycosterol rhamnosyltransferase, the terminal step in triose side-chain biosynthesis. Phytochemistry $68:$ 327-334.

Moehs CP, Allen PV, Friedman M, BelknapWR. 1997. Cloning and expression of solanidine UDP-glucose glucosyltransferase from potato. Plant J. 11: 227-236.

National Center for Biotechnology Information. www.ncbi. nlm.nih.gou/blastp.

Peksa A, Golubowska G, Rytel E, Lisiska G, Aniolowski K. 2002. Influence of harvest date on glycoalkaloid contents of three potato varieties. Food Chem. 78: 313-317.

Peksa A, Golubowska G, Aniolowski K, Lisinska G, Rytel E. 2006. Changes of glycoalkaloids and nitrate contents in potatoes during chip processing. Food Chem. 97: 151-156.

Percival G, Dixon G, Sword A. 1994. Glycoalkaloid concentration of potato tubers following continuous illumination. J. Sci. Food Agric. 66: 139-144.

Petersson EV, Arif U, Schulzova V, Krtková V, Hajšlová J, Meijer J, Andersson HC, Jonsson L, Sitbon F. 2013. Glycoalkaloid and calystegine levels in table potato cultivars subjected to wounding, light, and heat treatments. J. Agri. Food Chem. 61: 5893-5902.

Roddick JG, Rijnenberg AL. 1989. The acetylcholinesterase- inhibitory activity of steroidal glycoalkaloids and their aglycones. Phytochemistry 28: 2631-2634.

Sinden SL, Sanford LL, Webb RE. 1984. Genetic and environmental control of potato glycoalkaloids. Am. Potato J. 61: 141-156

Sleper DA, Poehlman JM. 2006. Breeding field crops, $5^{\text {th }}$ ed. Blackwell Publishing professional. 2121 State Avenue, Ames, Iowa.

Sorensen KK, Kirk HG, Olsson K, Labouriau R, Christiansen J. 2008. A major QTL and an SSR marker associated with glycoalkaloid content in potato tubers from Solanum tuberosum $\times$ S. sparsipilum located on chromosome I. Theor. Appl. Genet. 117: 1-9.

Stich B, Urbany C, Hoffmann P, Gebhardt C. 2013. Population structure and linkage disequilibrium in diploid and tetraploid potato revealed by genome-wide high density genotyping using the ColCAP SNP array. Plant Breed. 132: 718-724.

Smith DB, Roddick JG, Jones JL. 1996. Potato glycoalkaloids: Some unanswered questions. Trends Plant Sci. 7: 193-195.

Sun YI, Zhao Y, Wang L, Lou H, Cheng A. 2012. Cloning and expression analysis of squalene synthase, a key enzyme involved in antifungal steroidal glycoalkaloids biosynthesis from Solanum nigrum. Drug Discov. Therap. 6: 242-248.

Valkonen JP, Keskitalo M, Vasara T, Pietila L, Raman KV. 1996. Potato glycoalkaloids: A burden or a Blessing? Crit. Rev. Plant Sci. 15: 1-20.

Yang ZB, Park HS, Lacy GH, Cramer CL. 1991. Differential activation of potato 3-hydroxy-3methylglutaryl coenzyme-A reductase genes by wounding and pathogen challenge. Plant Cell 3: 397-405.

Yukimune Y, Tabata H, Higashi Y, Hara Y. 1996. Methyljasmonate-induced overproduction of paclitaxel and baccatin III in Taxus cell suspension cultures. Nat. Biotechnol. 14: 1129-1132.

Zhao J, Davis LC, Verpoorte R. 2005. Elicitor signal transduction leading to production of plant secondary metabolites. Biotechnol. Adv. 23: 283-333.

Zhao J, Zhu WH, Hu Q, He XW. 2000. Improved indole alkaloid production in Catharanthus roseus suspension cell cultures by various chemicals. Biotechnol. Lett. 22: 1221-1226. 